\title{
Cuprum and Cobalt Nano-Particles Influence on Bull-Calves' Growth and Development
}

\author{
Gennady Ivanovich Churilov ${ }^{1}$, Svetlana Dmitrievna Polishchuk ${ }^{2}$ and Anna Anatolievna Nazarova ${ }^{2}$ \\ 1. State Medical University, Ryazan 390026, Russia \\ 2. State Agrotechnological University, Ryazan 390044, Russia
}

Received: March 21, 2013 / Accepted: April 14, 2013 / Published: June 25, 2013.

\begin{abstract}
They have conducted the research to identify the possibility of increasing the abiotic polymerization intensity and efficiency both in the organism and in animals' muscular tissue. These tasks can be partially solved in a case of biogenous nano-metals usage such as cuprum and cobalt when adding them to the fodder. To estimate the meat productivity indexes they have formed black and white bull-calves groups. The nano-crystal cobalt ration additive for experimental bull-calves has led to live weight increase in 2 months per $6 \%$, in 4 months per $4.8 \%$, in 8 months per $11.7 \%$ and in 12 months per $19 \%$ in comparison with the controlled group. Amino-transferases content depending on the nano-metal has increased by the end of the experiment from $2.4 \%$ to $8.8 \%$ on retention of de Rittis index within the physiological norm. Essential amino acids content in blood has increased per 8\%-13\%. One can also see mineral substances increase in animals' muscular tissue. Estimation of meat chemical content and some quantitative indexes of meat productivity prove the conclusion about the positive influence of cuprum and cobalt nano-powders fodder additives.
\end{abstract}

Key words: Nano-powders, cuprum, cobalt, bull-calves, meat productivity.

\section{Introduction}

They have shown the possibility to increase the abiotic polymerization intensity and efficiency both in the organism and in animals' muscular tissue and correspondingly to grow skeletal musculature and improve meat qualitative content at the expense of better provision of metabolism processes with essential amino acids.

Nano-powders with 20-30 $\mathrm{nm}$ particles used in the research can be compared with cells and cellular structures size within $1 \mathrm{~nm}$ to $100 \mathrm{~nm}$. That is why in a case of nano-powders interaction with cellular structures one can see energy redistribution that can explain bio-ecological effects of nano-metals. Nano-powders are active only in a colloidal state where the process of nano-structuring takes place and definite correlation of free and charged particles is

Corresponding author: Svetlana Dmitrievna Polishchuk, doctor of technical science, research fields: nanopraticles, biotechnlogy, plant physiology, biochemictry and animal's physyology. E-mail: svpolishuk@mail.ru. formed. One can find nano-layers on the surface of bio-structures which posses definite energy store and are ready to change this energy and their reactivity with objects in contact.

In spite of some definite success in studying the nano-materials influence on living systems [1-7] we have got a lack in studying synthesis and body protein renewal objective laws and mechanisms regulating these processes in cattle offspring. Change mechanisms and protein synthesis ways knowledge opens a prospect of this process regulation within biological possibilities of the organism. The research actuality is connected with the possibility to develop new ways of protein and lipids metabolism regulation in order to increase the fodder protein bio-conversion and to forecast productive reactions and educe animals having high meat productivity potential.

Regulation of protein and lipids metabolism processes taking place in skeleton musculature is one of the real ways to optimize high-qualitative meat 
production. Metabolism is a quantitative process, so to increase animals' productivity one should have a clear-cut idea about possible loading with substrates-metabolites when providing effective protein synthesis. The endocrine system state and the level of available for digestion substrates (amino acids, glycose, fat acids etc.) appearing as a result of fodder raw nutrients transformation in the digestive tract have the most significant influence on protein metabolism processes in animals' bodies. The questions of regulating the protein syntheses, decay and deposit processes intensity by means of increasing availability for amino acids change are actual in recent years and are important for discovery and identification of mechanisms regulating the processes of meat productivity formation.

\section{Experiments}

To estimate cuprum and cobalt nano-powders influence on the intensity and efficiency of protein syntheses in animals they have formed three groups six black-and-white bull-calves aged 10 moths each on the principle of analogues [8].

They have processed cuprum and cobalt nano-powders having particles of 20-30 nm in suspensions with concentration $0.02-0.04 \mathrm{mg} / \mathrm{kg}$ of live weight with ultrasound PSB-5735-5 for $10 \mathrm{~min}$. Later they have added the nano-particles suspensions to the fodder of experiment animals every day during the research.

To study protein metabolism they have determined nutrients (nitrogen, phosphorus, calcium) digestibility and balance as well as the content of amino acids, rude protein and its fractions and ferments in blood.

They have determined blood biochemical indexes with the help of the clinic-diagnostic methods.

They have studied amino-acid content of muscles with automatic analyzer AAA-T 399. They have determined the animals' meat mineral content by atomic-emissive spectrometry method with inductive plasma (AES with INP). By the end of month 12 of the research they have slaughtered the animals and analyzed experimental animals indexes before and after the slaughter.

\section{Results and Discussion}

\subsection{Results of Determining Meat Productivity Indexes}

Meat productivity is characterized by both quantitative and qualitative indexes. Cattle meat is one of the basic food stuffs rich in protein. Cattle meat digestibility comprises $95 \%$.

They have determined meat productivity of controlled and experimental animals according to live weight (Table 1), daily average and gross increase.

The controlled animals live weight gain has had its peculiarities. The most dynamic live weight gain has taken place during the first six months up to one year. Live weight indexes of controlled animals at 6 months, one year and 18 months were corresponding to the physiological norms. It is necessary to point out that adding of nano-crystal metals to the experimental calves' ration has led to live weight increase beginning from the 2 nd month of the experiment.

Nano-crystal cobalt adding to the ration of the experimental calves has led to $6 \%$ increase of live weight increase in 2 months, $4.8 \%$ in 4 months, $11.7 \%$ in 8 months, $19 \%$ in 12 months in comparison with the controlled group.

Nano-crystal cuprum adding to the ration of the experimental calves has caused $11.3 \%$ live weight increase in 12 months in comparison with the controlled group.

One can explain live weight increase in a case of metal nano-powders adding to the animals' fodder by nutrients digestibility and fixation promoting live weight gain of experimental animals throughout the experiment.

Quantitative indexes of meat productivity depend mainly on growing and feeding conditions, and largely on the animal breed peculiarities, gender and age. That is why under otherwise identical conditions of the experiment the significant weight increase at 
Table 1 Live weight of controlled and experimental black-and-white bull calves, $\mathbf{k g}$.

\begin{tabular}{clll}
\hline Age (months) & Control & Experiment with cobalt & Experiment with cuprum \\
\hline 6 & $165.8 \pm 4.4$ & $183.2 \pm 3.8$ & $174.5 \pm 5.6$ \\
12 & $280.6 \pm 3.8$ & $318.1 \pm 4.8$ & $311.8 \pm 5.1$ \\
15 & $341.6 \pm 3.0$ & $389.0 \pm 3.1$ & $378.5 \pm 1.2$ \\
18 & $402.6 \pm 1.9$ & $459.8 \pm 8.3$ & $448.3 \pm 4.9^{*}$ \\
\hline
\end{tabular}

Note: ${ }^{*}-P>0.05$.

experimental calves' average daily and gross gains is connected with nano-metals adding to the fodder. Cobalt and cuprum physiological activities are significantly different but the nano-metals show similar results. This effect proves our assumption concerning the fact that ultra-fine metals have radically different mechanism of action in comparison with mineral salts and microelements chelates.

They have previously conducted numerous experiments about ferrum nano-powder influence on agricultural animals' meat productivity [9]. On the whole ferrum nano-powder has shown positive influence on meat productivity indexes and we have decided to have comparative tests of its action and that of cobalt and cuprum nano-powders.

\subsection{Identification of Protein Metabolism Indexes}

Cobalt and cuprum nano-powders adding to the fodder of black-and-white bull-calves has had a significant impact on the process of protein metabolism. Protein metabolism proceeds with transaminases active participation (AST, ALT). By the end of the experiment one can see $8.2 \%$ ALT and $4.7 \%$ AST increase in the blood serum of animals fed with cobalt nano-powder. Cuprum nano-powders have increased ALT content per $8.8 \%$ and that of AST per $2.4 \%$. However, the fact that de Rittis index both in the controlled and experimental groups was within the physiological range when aminotransferases content increase (Table 2) indicates the bull-calves normal development.

Simultaneously with that one can see urea and creatinine reduction in blood indicating nitrogen compounds fixation increase. This is proved by free amino acids presence in animals' blood and muscles.
Table 2 Blood biochemical indexes of bull-calves having cobalt and cuprum nano-powders in the fodder.

\begin{tabular}{lccl}
\hline Figures & Control & $\begin{array}{r}\text { Experiment } \\
\text { with cobalt }\end{array}$ & $\begin{array}{l}\text { Experiment } \\
\text { with cuprum }\end{array}$ \\
\hline ALT $(\mathrm{mmol} / \mathrm{l})$ & $0.85 \pm 0.01$ & $0.92 \pm 0.04$ & $0.89 \pm 0.03$ \\
AST (mmol/l) & $1.25 \pm 0.06$ & $1.36 \pm 0.04$ & $1.28 \pm 0.02$ \\
$\begin{array}{l}\text { De Rittis index } \\
\text { (AST/ALT) }\end{array}$ & 1.47 & 1.48 & 1.44 \\
Urea (mmol/l) & $3.61 \pm 0.073 .21 \pm 0.05$ & $3.21 \pm 0.09$ \\
Creatinine (mmol/l) & $73 \pm 0.15$ & $70 \pm 0.11$ & $71 \pm 0.1$ \\
\hline
\end{tabular}

Note: ${ }^{*}-P<0.05-0.001$ in comparison with control.

\subsection{Animals' Amino-Acid Blood}

We have studied amino-acid blood of controlled and experimental animals at the beginning, middle and end of the experiment. According to amino-acid blood change nano-powders has significantly activated nitrogen metabolism in experimental animals throughout the experiment. One can see dynamic increase of free essential and non-essential amino acids in blood. By the end of the experiment we have noticed considerable increase in amino acids in bull-calves' blood having cobalt nano-powder in the fodder (per 26.8\%) and cuprum (per 21.9\%) in comparison with the control group (Table 3 ).

\subsection{Amino Acids in the Longest Back Muscle}

At the end of the experiment they have slaughtered the animals and analyzed amino acids in the longest back muscle. The results of the investigation are presented in Table 4.

Essential amino acids in bull-calves' meat protein have increased in comparison with control in a case of cobalt nano-powder usage per $13.3 \%$ and cuprum nano-powder per $7.9 \%$. The nano-powders have promoted a significant increase of glicine, histidin, methionine and serine in muscles of experimental 
Table 3 Amino-acid blood of animals having cobalt and cuprum nano-powders in the fodder (after 12 months of the experiment), mg\%.

\begin{tabular}{lccc}
\hline Amino acids & Control & Experiment with cobalt & Experiment with cuprum \\
\hline Lysin & $6.60 \pm 0.01$ & $7.50 \pm 0.04$ & $7.11 \pm 0.05$ \\
Histidin & $4.30 \pm 0.05$ & $4.81 \pm 0.07$ & $5.30 \pm 0.03$ \\
Arginine & $11.81 \pm 0.04$ & $12.90 \pm 0.05^{*}$ & $12.90 \pm 0.06$ \\
Threonine & $8.50 \pm 0.02$ & $9.61 \pm 0.03$ & $9.10 \pm 0.02$ \\
Cystine & $4.20 \pm 0.06$ & $4.71 \pm 0.09$ & $4.90 \pm 0.06$ \\
Valine & $4.40 \pm 0,07$ & $5.61 \pm 0.17$ & $6.50 \pm 0.01^{*}$ \\
Methionine & $1.21 \pm 0.57$ & $2.51 \pm 0.13$ & $2.11 \pm 0.05$ \\
Isoleucine & $3.11 \pm 0.62$ & $4.61 \pm 0.34^{*}$ & $4.50 \pm 0.00$ \\
Leucine & $2.21 \pm 0.04$ & $4.40 \pm 0.45$ & $4.30 \pm 0.01$ \\
Finilalanin & $2.71 \pm 0.02$ & $3.31 \pm 0.52$ & $2.81 \pm 0.07$ \\
Glicine & $3.41 \pm 0.04^{*}$ & $6.51 \pm 0.85$ & $5.70 \pm 0.05$ \\
Asparagic acid & $4.80 \pm 0.08$ & $5.51 \pm 0.11$ & $4.31 \pm 0.01$ \\
Serine & $8.01 \pm 0.07$ & $8.21 \pm 0.12$ & $8.51 \pm 0.27$ \\
Glutanic acid & $4.51 \pm 0.04$ & $7.61 \pm 0.07$ & $6.61 \pm 0.45$ \\
Proline & $6.01 \pm 0.06$ & $7.80 \pm 0.06^{*}$ & $7.61 \pm 0.62$ \\
Alanine & $3.51 \pm 0.02$ & $4.81 \pm 0.03$ & $3.61 \pm 0.34$ \\
Tyrosine & $2.20 \pm 0.01$ & $2.91 \pm 0.09$ & $3.41 \pm 0.11^{*}$ \\
\hline Amount of amino acids & 81.4 & 103.2 & 99.2 \\
\hline
\end{tabular}

Note: ${ }^{*}-P<0.05-0.001$ in comparison with control.

Table 4 Metal nano-powders influence on amino acids in muscles, \%.

\begin{tabular}{lccc}
\hline Amino acids & Control & Experiment with cobalt & Experiment with cuprum \\
\hline Essential amino acids & & & \\
\hline Histidin & $2.40 \pm 0.02$ & $2.69 \pm 0.02$ & $2.71 \pm 0.02$ \\
Lysin & $4.71 \pm 0.03$ & $5.27 \pm 0.05$ & $5.07 \pm 0.03$ \\
Fenilalanin & $2.58 \pm 0.01$ & $2.52 \pm 0.02$ & $2.40 \pm 0.02^{*}$ \\
Methionine & $1.74 \pm 0.01^{*}$ & $2.31 \pm 0.03$ & $2.09 \pm 0.02$ \\
Threonine & $2.77 \pm 0.02$ & $3.12 \pm 0.04$ & $3.01 \pm 0.04$ \\
Leucine & $4.88 \pm 0.05$ & $5.46 \pm 0.05$ & $5.21 \pm 0.05$ \\
Isoleucine & $2.13 \pm 0.02$ & $2.54 \pm 0.02$ & $2.35 \pm 0.03$ \\
Valine & $2.48 \pm 0.03^{*}$ & $2.93 \pm 0.04$ & $2.72 \pm 0.03$ \\
\hline Total: & $23.69 \pm 0.06$ & $26.84 \pm 0.05$ & $25.56 \pm 0.08$ \\
\hline Non-essential amino acid & & & $3.50 \pm 0.03$ \\
\hline Arginine & $3.43 \pm 0.03$ & $3.80 \pm 0.04$ & $3.01 \pm 0.02$ \\
Glicine & $3.13 \pm 0.03$ & $3.06 \pm 0.03^{*}$ & $0.72 \pm 0.02$ \\
Cystine & $0.66 \pm 0.01$ & $0.93 \pm 0.03$ & $2.10 \pm 0.02^{*}$ \\
Tyrosine & $2.04 \pm 0.01$ & $2.18 \pm 0.02$ & $5.83 \pm 0.01$ \\
Glutanic acid & $10.58 \pm 0.01$ & $11.42 \pm 0.03^{*}$ & $3.61 \pm 0.03$ \\
Asparagic acid & $5.87 \pm 0.05$ & $6.25 \pm 0.06$ & $2.82 \pm 0.03$ \\
Alanine & $3.56 \pm 0.03$ & $3.84 \pm 0.03$ & $2.28 \pm 0.03$ \\
Serine & $2.68 \pm 0.01$ & $2.93 \pm 0.04$ & $34.50 \pm 0.07$ \\
Proline & $2.83 \pm 0.02$ & $2.77 \pm 0.03^{*}$ & 0.74 \\
\hline Total: & $34.78 \pm 0.06$ & $37.18 \pm 0.09$ & \\
\hline Correspondence of essential to & 0.68 & 0.72 & \\
non-essential amino acids & & & \\
\hline Note $P<0.05-0.001$ & & & \\
\hline
\end{tabular}

Note: ${ }^{*}-P<0.05-0.001$ in comparison with control. 
animals that participate in other amino acids synthesis, blood cells production, stimulate antioxidants accumulation (vitamins $\mathrm{C}, \mathrm{E}$ ).

Blood biochemical indexes reflect many physiological and biochemical processes happening in the process of metabolism including different changes of physiological state under the influence of the studied factors.

\subsection{Mineral Components in Animals' Muscular Tissue}

An important index of biological value of meat is muscles' mineral composition. Mineral composition in meat of controlled and experimental bull-calves is presented in Table 5.

The results of the experiment have shown that nano-metals do not accumulate in animals' body that is proved by mineral composition of blood and muscles but other substances composition changes. Cobalt nano-powder has increased calcium (per $31.8 \%$ ), ferrum $(30.8 \%)$, kalium $(19.2 \%)$, magnesium $(17.6 \%)$, natrium $(20.5 \%)$ as compared with the control group. Cuprum nano-powder has increased ferrum (37.5\%), kalium (15.3\%), magnesium (23.5\%), manganese $(45 \%)$, natrium $(8.8 \%)$ as compared with the control group.
The content of cobalt, cuprum and heavy metals is less than control.

\subsection{Meat Productivity Figures}

They have identified the slaughter rates and internal organs weight from meat productivity quantitative figures (Table 6). The controlled animals' figures are in the standard range.

Experimental animals pre-slaughter weight that have had cobalt nano-powders has exceeded the mass of controlled ones per $9.2 \%$, and that with cuprum nano-powder per $6.4 \%$.

Cobalt nano-powder introduction into the fodder of black-and-white bull-calves has also promoted significant increase in steam carcass weight per $18.7 \%$ that of carcass yield per $4.2 \%$, bones in the carcass content per $3 \%$, slaughter weight per $16.9 \%$ and slaughter yield per $3.7 \%$ in comparison with controlled animals. Internal fat weight in the experiment has exceeded that of control per $27.4 \%$ and fat yield in the experiment has been more than in the control per $0.5 \%$. Cuprum nano-powder in bull-calves ration has led to the increase of steam carcass weight per $14.0 \%$, carcass yield per $3.5 \%$, fat per $0.3 \%$, and slaughter yield per $2.1 \%$.

Table 5 Metal nano-powders influence on mineral composition of black-and-white bull-calves' muscles, mg/kg.

\begin{tabular}{|c|c|c|c|}
\hline \multirow{2}{*}{ Substance } & \multicolumn{3}{|c|}{ Groups } \\
\hline & Control & Experiment with cobalt & Experiment with cuprum \\
\hline Boron (B) & $26 \pm 0.1$ & $25 \pm 0.1^{*}$ & $26 \pm 0.1$ \\
\hline Calcium (Ca) & $220 \pm 2^{*}$ & $290 \pm 2$ & $220 \pm 2$ \\
\hline Cobalt (Co) & $0.10 \pm 0.003$ & $0.12 \pm 0.003^{*}$ & $0.12 \pm 0.004^{*}$ \\
\hline Chrome (Cr) & $1.4 \pm 0.04$ & $1.3 \pm 0.06$ & $1.3 \pm 0.05$ \\
\hline Cuprum $(\mathrm{Cu})$ & $2.5 \pm 0.02^{*}$ & $2.8 \pm 0.03$ & $2.7 \pm 0.04$ \\
\hline Ferrum $(\mathrm{Fe})$ & $240 \pm 2$ & $314 \pm 3$ & $330 \pm 4^{*}$ \\
\hline Kalium (K) & $2.6^{*} 10^{3 * *}$ & $3.1 * 10^{3}$ & $3.0 * 10^{3}$ \\
\hline Magnesium (Mg) & $170 \pm 1.5$ & $200 \pm 1.9^{*}$ & $210 \pm 1.4$ \\
\hline Manganese (Mn) & $5.1 \pm 0.04$ & $5.6 \pm 0.06$ & $7.4 \pm 0.08^{*}$ \\
\hline Molybdenum (Mo) & $0.2 \pm 0.005$ & $0.2 \pm 0.003^{*}$ & $0.2 \pm 0.002$ \\
\hline Natrium (Na) & $340 \pm 3$ & $410 \pm 5$ & $370 \pm 4$ \\
\hline Nickel (Ni) & $<0.1$ & $<0.1$ & $<0.1$ \\
\hline Plumb (Pb) & $<0.1$ & $<0.1$ & $<0.1$ \\
\hline Selenium (Se) & $0.5 \pm 0.003^{*}$ & $0.4 \pm 0.002$ & $0.5 \pm 0.003^{*}$ \\
\hline Strontium (Sr) & $<0.1$ & $<0.1$ & $<0.1$ \\
\hline
\end{tabular}

Note: ${ }^{*}-P<0.05,{ }^{* *}-P<0.05-0.001$ in comparison with control. 
Table 6 Slaughter rates of black-and-white bull-calves.

\begin{tabular}{llll}
\hline \multirow{2}{*}{ Figures } & \multicolumn{3}{c}{ Groups } \\
\cline { 2 - 4 } & Control & Experiment with cobalt & Experiment with cuprum \\
\hline Body weight (kg) & $402.6 \pm 1.91$ & $459.8 \pm 8.32$ & $448.3 \pm 4.90^{*}$ \\
pre-slaughter & 385 & 446 & 435 \\
Steam carcass weight (kg) & 178.3 & $256.8^{*}$ & 235.7 \\
Carcass yield (\%) & 46.3 & 57.5 & 54.2 \\
Internal fat weight (kg) & 24.2 & 29.0 & 28.3 \\
Fat yield (\%) & 13.6 & 11.3 & 12.0 \\
Bones in the carcass (\%) & 15.0 & 18.0 & 17.0 \\
Slaughter weight, (kg) & 221.4 & 327.8 & 313.9 \\
Slaughter yield (\%) & 57.5 & 73.5 & 72.2 \\
\hline
\end{tabular}

Note: ${ }^{*}-P>0.05$.

Table 7 Chemical Composition of Meat (\%).

\begin{tabular}{llll}
\hline \multirow{2}{*}{ Figures } & \multicolumn{2}{c}{ Groups } \\
\cline { 2 - 4 } & Control & Experiment with cobalt & Experiment with cuprum \\
\hline Water & $77.6 \pm 0.5^{*}$ & $72.3 \pm 0.6$ & $71.5 \pm 0.8$ \\
Dry matter: & $22.4 \pm 0.3$ & $27.7 \pm 0.4$ & $28.5 \pm 0.2^{*}$ \\
Protein & $18.5 \pm 0.1$ & $21.4 \pm 0.2$ & $21.0 \pm 0.3$ \\
Fat & $12.1 \pm 0.3$ & $13.5 \pm 0.2$ & $13.2 \pm 0.4$ \\
Ash & $0.91 \pm 0.02$ & $1.21 \pm 0.03$ & $1.11 \pm 0.02$ \\
Energy value, $\mathrm{kJ} / \mathrm{gr}$ & $377 \pm 3$ & $424 \pm 4$ & $415 \pm 5$ \\
\hline
\end{tabular}

Note: ${ }^{*}-P \leq 0.01$.

The autopsy has shown that the form, color and size of all internal organs of the animals fed with metals nano-powders have been within the physiological norm characteristic for the animals of this type and age. All of the above suggests the absence of possible pathologies and toxicity of the studied bio-actives.

\subsection{Chemical Composition of Meat}

Table 7 presents the results of cobalt and cuprum nano-powders influence on the chemical composition of meat.

Cobalt nano-powder has reduced water content in meat per $5.4 \%$ in comparison with control, increased protein content per $2.9 \%$ and ash, i.e. minerals per $0.3 \%$ in comparison with control. The energy value of meat has increased per $12.5 \%$. Cuprum nano-powder introduction has reduced water in meat per $6.1 \%$. One can also see the increase of protein (per 2.5\%) and ash (per $0.2 \%$ ) as compared with control. The energy value of meat has increased up to $10.1 \%$. According to the data metals nano-powders introduction improves the chemical composition of animals' meat making it more nutritious and full.

\section{Conclusions}

The conducted research has shown that one can use cobalt and cuprum nano-powders as stimulators of metabolism processes including the protein one that increase meat productivity and improve the animals' general physiological state.

Under the influence of metals nano-particles the figures of protein metabolism in blood have changed. So crude protein in blood and protein blood index, albumin and globulin fractions content have increased. One can also see ALT ferments increase (4.7\%-8.2\%) and AST (2.4\%-8.8\% compared with control) with the reduction of protein breakdown products in blood: urea $(11 \%)$ and creatinine $(2.7 \%-4.1 \%)$ testifying the increase of nitrogenous compounds uptake in the body.

By the end of the experiment we have noticed the increase of free amino acids both in blood (per $21.9-26.8 \%$ ) and in muscle tissue (per $6.9 \%$ as 
compared with control) that proves protein metabolism intensity increase.

So, metal nano-powders adding to the fodder leads to the improvement of meat productivity qualitative figures of the black-and-white breed that is expressed in intensive growth of muscle tissue, fat tissue growth decrease and more nutritious meat.

The veterinary-sanitary expertise suggests that cobalt and cuprum nano-powder can be used as dietary supplements to agricultural animals' fodder. Products of animal slaughter that were grown with their usage correspond to all norms of ecological safety.

\section{References}

[1] G.I. Churilov, L.E. Ampleyeva, A.A. Nazarova, S.D. Polishchuk, Cobalt influence on physiological state and morphological and biochemical indexes of animals' blood, Russian Medico-Biological Vestnik Ryazan 4 (2007) 34-41.

[2] G.I. Churilov, L.E. Ampleyeva, A.A. Nazarova, S.D. Polishchuk, Influence of vetch treated with ultra-fine ferrum powder on morphological and biochemical indexes of blood, Russian Medico-Biological
Vestnik Named after I.P. Pavlov. Ryazan 1 (2008) 70-74.

[3] A.A. Nazarova, T.V. Zheglova, S.D. Polishchuk, G.I. Churilov, Y.N. Ivanycheva, G.E. Folmanis, et al., Ultra-fine ferrum and cuprum action on rabits in a case of their adding to the fodder, Rabbit Breeding and Fur-Farming 6 (2008) 8-10.

[4] N. Zenova, A. Nazarova, S. Polishchuk, Ultra-fine ferrum influence on cattle growth and development, Milk and Meat Animal Breeding 1 (2010) 30-32.

[5] E. Ilyichev, A. Nazarova, S. Polishchuk, V. Inozemtsev, Ration digestibility and nutrient balance when feeding the calves with cobalt and cuprum nano-powders, Milk and Meat Animal Breeding 5 (2011) 27-29.

[6] O.V. Kulikova, A.A. Nazarova, S.D. Polishchuk, Nano-crystal metalls influence on hematopoiesis when adding to rabbits' ration, Vestnik FSBEI HPE RSATU 2 (14) (2012) 70-73.

[7] A.A. Nazarova, S.D. Polishchuk, Cattle metabolism peculiarities when adding cobalt nano-particles to ration, Materials of VII International Symposium Fundamental and Applied Scientific Problems Moscow: RAS 3 (2012) 257-266.

[8] A.I. Ovsyannikov, Basis of Experimental Work in Animal Breeding, Kolos, 1976, p. 304.

[9] E. Ilyichev, Ferrum nano-powder influence on meat productivity of cattle offspring, Milk and Meat Animal Breeding 1 (2011) 24-25. 